\title{
PENGARUH IKLAN KATALOG TERHADAP KEPUTUSAN PEMBELIAN DI INDOMARET SINDANGSARI TANJUNG BINTANG
}

\author{
Anastasia Febriana Sidabalok¹, Elysabet Andriyani² \\ Sekolah Tinggi Ilmu Ekonomi Gentiaras Bandar Lampung \\ Email: Eliandriyani@.gmail.com
}

\section{ABSTRACT}

This study belongs to a quantitative research which aims to $d$ the effect of catalog advertisement towards buying decision on Indomaret in Sindangsari Tanjung Bintang. The problem of this study is how the catalog advertisement can influence purchasing decisions made by consumers.

The subject in this study is consumers at Indomaret Sindangsari Tanjung Bintang that consisting of 39 men and 69 women. The instrument used in this research is a questionnaire that sourced from variable operational development. The research instrument amounted to 100 items with a determination coefficient of 0,573 . Thus, it can be conclude that catalog advertisement has a significant effect on purchasing decisions.

This study produced the regression equation that positively valued at $Y=2,242+0,766 X . R$ square shows a number 0,573 it means advertisement catalog affect the purchasing decision as much as $57.3 \%$ and the rest are influenced by other factors. The results of the $T$ test show a calculated value of 11.466 greater than 0, 196 which means that Ho is rejected and Ha is accepted. This states that catalog advertisement variables influence the purchasing decisions.

Keyword : catalog advertisement, purchasing decisions

\section{PENDAHULUAN}

\subsection{Latar Belakang}

Perkembangan usaha dalam dunia ritel sedang mengalami penurunan. Hal ini dapat dilihat dari beberapa ritel yang mulai menutup sebagian gerainya seperti Giant Supermarket, PT Ramayana, Milenium, Matahari Departemen Store sampai Lotus Departement Store. Selain persaingan usaha antar ritel yang semakin ketat, tutupnya beberapa gerai tersebut terjadi karena adanya perubahan gaya berbelanja masyarakat.

Ada pergeseran preferensi belanja konsumen dari konsumsi berbasis produk ke konsumsi berbasis pengalaman terutama di kalangan milenial. Tren ini membuat masyarakat memutuskan mengurangi belanja barang di sejumlah ritel secara perlahan dan lebih banyak memilih untuk travelling ke tempat yang baru.

Kesuksesan perusahaan dapat diukur dengan seberapa banyak keuntungan dan barang yang dapat dijual di pasar. Sebelum melakukan penjualan maka dibutuhkan strategi pemasaran yang harus dilakukan oleh perusahaan. Sebagai salah satu bagian dari konsep pemasaran, variabel marketing mix adalah promosi yang didalamnya terdapat lima perangkat utama yaitu : advertising (periklanan), sales promotion (promosi penjualan), public relation (hubungan masyarakat), personal selling (penjualan perorangan), dan direct marketing (pemasaran langsung), (Maxmonroe, 2019).

Pada hakikatnya promosi adalah suatu bentuk komunikasi pemasaran yang merupakan suatu bentuk aktivitas untuk berusaha menyebarkan informasi, mempengaruhi atau membujuk, dan mengingatkan pasar sasaran atas perusahaan dan produknya agar bersedia menerima, membeli dan loyal pada produk yang ditawarkan perusahaanyang bersangkutan. Dari berbagai macam bentuk promosi, diantaranya terdapat promosi yang dilakukan melalui media katalog untuk mempengaruhi konsumen berbelanja. 
Katalog adalah alat publikasi yang digunakan perusahaan sebagai cara untuk mempromosikan produk dan layanan mereka. Katalog dalam dunia bisnis bagaikan sebuah jembatan komunikasi antara produsen dan konsumen. Karena katalog merupakan sarana bagi perusahaan untuk menyajikan secara rinci cakupan produk dan jasa langsung kepada konsumen. Konsumen akan merasa seperti mendapatkan informasi yang lengkap tanpa harus mendatangi tempat produsen. Hanya dengan membaca katalog para konsumen bisa dengan mudah memutuskan untuk membeli produk mana yang mereka sukai. Penghematan waktu dan efektifitas akan tercapai melalui sarana katalog karena katalog merupakan sarana bagi perusahaan untuk menyajikan secara rinci cakupan produk dan jasa langsung kepada konsumen.

Dari fenomena tutupnya berbagai gerai ritel di atas, PT. Indomarco Prismatama selaku induk manajemen dari Indomaret harus mencoba berbagai inovasi untuk bisa terus menjalankan usahanya. Saat ini promosi melalui media katalog semakin gencar dilakukan oleh PT. Indomarco Prismatama karena katalog merupakan salah satu media promosi yang sangat diminati oleh konsumen baik secara online maupun katalog secara fisik (majalah franchise, 2019).

Bisnis ritel di Lampung Selatan terutama Desa Sindangsari Tanjung Bintang semakin hari dirasakan semakin ramai. Persaingan bisnis menunjukkan perkembangan yang cukup pesat namun tidak menjadi halangan bagi para pengusaha ritel untuk membuka outlet baru ataupun menambah jumlah outlet yang sudah dimiliki. Dengan semakin meningkatnya perkembangan bisnis ritel baik besar maupun kecil serta banyaknya jumlah supermarket/minimarket/toko di desa Sindangsari Tanjung Bintang menimbulkan persaingan yang kompetitif dimana setiap supermarket /minimarket/toko berusaha untuk memperoleh pangsa pasar seluas-luasnya, dan konsumen sebanyak-banyaknya.

Salah satu perusahaan yang bergerak dalam bidang retailer minimarket di desa Sindangsari Tanjung Bintang adalah PT. Indomarco Prismatama, atau yang lebih dikenal dengan nama Indomaret. Penulis tertarik untuk meneliti bagaimana Indomaret dapat bertahan ditengah-tengah tren penutupan gerai-gerai toko ritel modern selain juga ancaman persaingan dari toko-toko ritel sejenis di desa Sindangsari.

Dari hasil studi pendahuluan yang penulis lakukan pada bulan April 2019 terhadap 30 responden konsumen Indomaret di Indomaret Sindangsari Tanjung Bintang, dapat diketahui presentase pengaruh iklan katalog terhadap konsumen sebagi berikut:

\section{Gambar 1.}

Diagram Perbandingan Jumlah Responden Tentang Iklan Katalog

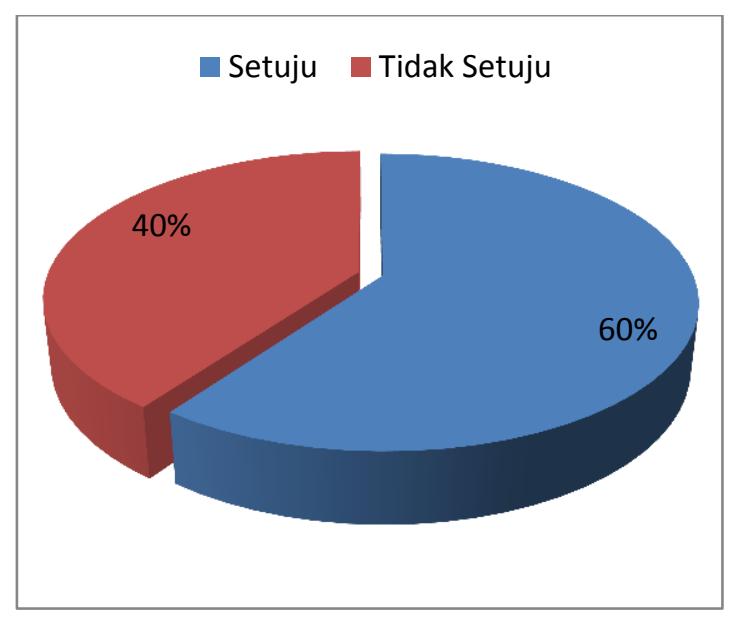

Sumber : data diolah, 2019

Diagram di atas menunjukkan bahwa dari 30 responden, terdapat 12 orang atau 40\% konsumen menyatakan tidak setuju iklan katalog berpengaruh terhadap keputusan pembelian sedangkan 18 konsumen lainnya atau $60 \%$ menyatakan setuju.

\subsection{Perumusan Masalah}

Bagaimana pengaruh iklan katalog terhadap keputusan pembelian di Indomaret Sindangsari Tanjung Bintang ?

\subsection{Tujuan Penelitian}

Untuk menganalisis bagaimana pengaruh iklan katalog terhadap keputusan pembelian di Indomaret Sindangsari Tanjung Bintang. 


\section{TINJAUAN PUSTAKA}

\subsection{Iklan Katalog}

Iklan sebagai struktur dan komposisi komunikasi informasi yang bersifat nonpersonal, umumnya dilakukan dengan berbayar yang dicirikan dengan persuasif, berisi tentang produk (barang, jasa, atau ide) yang diidentifikasikan sebagai sponsor melalui berbagai media (Junaedi, 2013).

Katalog merupakan media dalam komunikasi visual yang memuat informasi suatu produk. Hal ini dapat dilakukan untuk produk barang dalam jumlah yang banyak" (Tinarbuko, 2015). Katalog adalah alat publikasi yang digunakan perusahaan sebagai cara untuk mempromosikan produk dan layanan mereka. Grafis memungkinkan berbagai macam perusahaan untuk menginformasikan kepada calon pelanggan dan pelanggan yang sudah ada tentang harga dan fitur produk mereka dalam rangka untuk mendorong penjualan mereka. Katalog adalah sarana bagi perusahaan untuk menyajikan secara rinci cakupan produk dan jasa, langsung kepada pelanggan.

Maka dalam penelitian ini konsep iklan katalog didefinisikan sebagai sumber informasi yang bertujuan untuk menginformasikan produk yang ditawarkan dan menciptakan permintaan awal, membujuk dan mempengaruhi konsumen untuk membeli produk yang ditawarkan, serta mengingatkan konsumen mengenai keberadaan suatu produk serta berupaya melekatkan nama atau merek produk tertentu di benak konsumen melalui alat publikasi visual yang menyajikan gambar, deskripsi produk, termasuk harga diskon dan penawaran khusus perusahaan. Dengan indikator yaitu informasi, bahasa, perhatian, keyakinan dan daya tarik yang diungkapkan oleh (Tjiptono, 2011) dan (Sagalaart, 2019).

\subsection{Keputusan Pembelian}

Proses pembelian yang spesifik terdiri dari urutan kejadian sebagai berikut: pengenalan masalah, pencarian informasi, evaluasi alternatif, keputusan pembelian, dan perilaku pasca pembelian (Kotler, 2012). Model dibawah ini mempunyai anggapan bahwa para konsumen melakukan lima tahap dalam melakukan pembelian. Kelima tahap tersebut tidak selalu terjadi, khususnya dalam pembelian yang tidakmemerlukan keterlibatan tinggi dalam pembelian. Para konsumen bisa melewati beberapa tahap dan urutannya tidak sesuai.

Gambar 2.

Tahapan Proses Keputusan Pembelian Konsumen

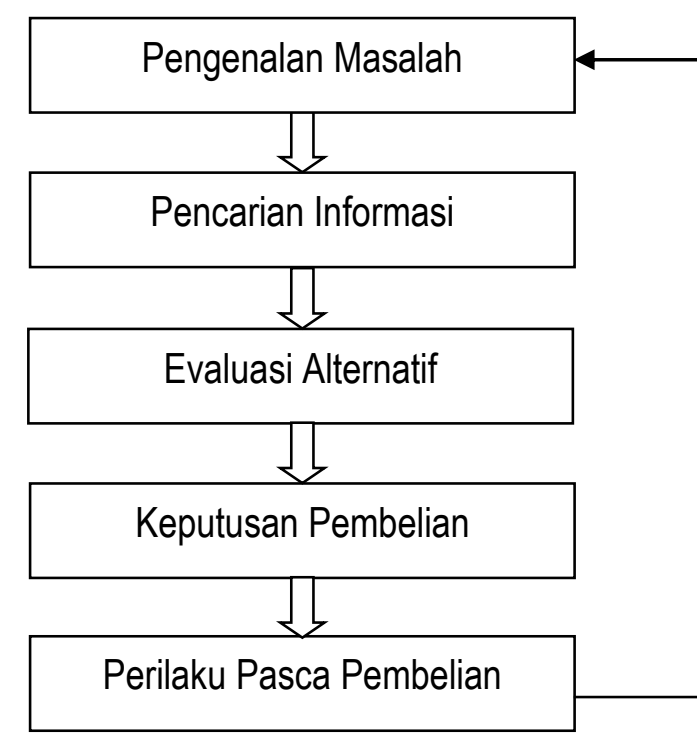

Sumber : Kotler, 2012

Proses pembelian di atas dimulai dengan pengenalan terhadap masalah atau kebutuhan, yaitu ketika pembeli menyadari perbedaan antara keadaan yang sebenarnya dan keadaan yang diinginkan. Kebutuhan itu bisa digerakkan oleh rangsangan dari dalam diri atau internal jika kebutuhan normal seseorang muncul ke tingkat yang tinggi, dorongan kebutuhan juga dapat dipicu oleh rangsangan dari luar diri atau eksternal.

Setelah konsumen mengenali kebutuhannya, maka tahap pencarian informasi (information search). Dalam hal ini konsumen akan berusaha untuk mencari lebih banyak informasi tentang produk yang dibutuhkan melalui iklan di media cetak atau elektronik, bertanya kepada orang lain atau bahkan mendatangi langsung perusahaan yang diinginkan.

Melalui pencarian informasi, maka calon pembeli akan menentukan beberapa 
alternatif keputusan yang dapat dievaluasi secara rasional, sehingga dapat ditentukan alternatif mana yang paling menguntungkan. Karena itu setelah tahap pencarian informasi dilakukan, maka tahap berikutnya adalah tahap evaluasi alternatif (evaluation of alternative). Dalam tahap ini calon pembeli melakukan evaluasi atas produk yang mungkin dinilai dari merek mana yang lebih baik, bagaimana kekuatan, keuntungan dan manfaatnya. Setelah melakukan penilaian, maka akan diambil keputusan membeli atau tidak membeli. Pembeli mempunyai caranya sendiri dalam menangani informasi yang diperoleh. Jika keputusan membeli, maka perlu ditetapkan toko mana, berapa jumlahnya, banyaknya uang yang tersedia, merek, warna, tipe, atau besarnya.

Apabila barang yang dibeli ternyata tidak memberikan kepuasan yang diharapkan, maka konsumen akan merubah sikapnya terhadap barang tersebut menjadi negatif bahkan mungkin akan menolaknya dari daftar pilihan. Sebaliknya, bila konsumen mendapatkan kepuasan dari barang yang dibelinya maka keinginan untuk membeli lagi barang tersebut cenderung menjadi lebih kuat.

Dari tahapan proses keputusan pembelian di atas dapat disimpulkan bahwa keputusan pembelian adalah perilaku pembelian seseorang dalam menentukan suatu pilihan produk untuk mencapai kepuasan sesuai kebutuhan dan keinginan konsumen yang meliputi pengenalan masalah, pencarian informasi, evaluasi terhadap alternatif pembelian, keputusan pembelian, dan perilaku setelah pembelian.

Keputusan pembelian adalah proses merumuskan berbagai alternatif tindakan guna menjatuhkan pilihan pada salah satu alternatif tertentu untuk melakukan pembelian" (Sumarwan, 2011).Keputusan adalah hasil pemecahan masalah yang dihadapinya dengan tegas. Hal itu berkaitan dengan jawaban atas pertanyaan-pertanyaan mengenai "apa yang harus dilakukan" dan seterusnya mengenai unsur perencanaan. Dapat juga dikatakan bahwa keputusan itu sesungguhnya merupakan hasil proses pemikiran yang berupa pemilihan satu diantara beberapa alternatif yang dapat digunakan untuk memecahkan masalah yang dihadapinya (Sangadji dan Sopiah, 2013).

Berdasarkan definisi diatas, disimpulkan bahwa keputusan pembelian adalah tindakan yang dilakukan oleh konsumen untuk melakukan pembelian sebuah produk berdasarkan alternatif-alternatif pilihan dan hasil evaluasi yang telah dibuat.

\subsection{Hipotesis}

Diduga terdapat pengaruh iklan katalog terhadap keputusan pembelian di Indomaret Sindangsari Tanjung Bintang.

\section{METODOLOGI PENELITIAN}

\subsection{Jenis Penelitian}

Penelitian evaluasi adalah penelitian yang dilakukan dengan mengumpulkan data atau informasi, untuk dibandingkan dengan kriteria kemudian diambil kesimpulan. Kesimpulan inilah yang kemudian disebut hasil evaluasi. Lokasi penelitian dilaksanakan di desa Sindangsari Tanjung Bintang pada bulan April 2019 sampai dengan bulan Juli 2019.

\subsection{Populasi Dan Sampel}

Populasi sasaran dalam penelitian ini adalah konsumen Indomaret yang ada di Desa Sindangsari Tanjung Bintang. Jumlah sampel dalam penelitian ini adalah 100 responden, dengan teknik sampling yang digunakan dalam penelitian ini adalah Snowball Sampling.

\subsection{Teknik Pengumpulan Data}

Data primer yakni data yang diperoleh dari hasil jawaban responden melalui penyebaran kuesioner dan data sekunder yaitu data yang diperoleh dari dokumen-dokumen perusahaan atau arsip perusahaan, serta bahan kepustakaan dan karangan ilmiah yang dapat mendukung penelitian ini.

\subsection{Teknik Analisis Data}

\section{Uji Validitas}

Suatu kuesioner dikatakan valid jika mempunyai validitas tinggi yaitu corrected item $>0,30$, sebaliknya kurang valid jika nilai corrected item $<0,30$. Metode korelasi yang digunakan adalah Pearson Product Moment 
$r=\frac{n \sum X Y-\left(\sum X\right)\left(\sum Y\right)}{\sqrt{\left\{n \sum X^{2}-\left(\sum X\right)^{2}\right\}\left\{\left(n \sum Y^{2}\right)-\left(\sum Y\right)^{2}\right\}}}$

Dimana :

$r \quad=$ Koefisien validitas item yang dicari

$\mathrm{n} \quad=$ Banyaknya responden

$\sum X=$ Total jumlah variabel $X$

$\sum Y \quad=$ Total jumlah Variabel $Y$

$\sum X^{2}=$ Kuadrat total jumlah Variabel $X$

$\sum Y^{2}=$ Kuadrat total jumlah Variabel $Y$

$\sum X Y=$ Kuadrat total jumlah Variabel $X$ dan $Y$

\section{Uji Reliabilitas}

Uji reliabilitas dilakukan dengan uji Alpha Cronbach. Rumus Alpha Cronbach sebagai berikut:

$$
r_{11}=\left[\frac{k}{(k-1)}\right]\left[1-\frac{\sum \sigma^{2} \mathrm{~b}}{\sigma^{2} t}\right]
$$

Dimana :

r11 = Koefisien reliabilitas Alpha Cronbach

$\mathrm{k}=$ = Jumlah item pertanyaan yang diuji

$\sum \sigma^{2 b}=$ Jumlah varians butir

$\sigma^{2 t} \quad=$ Varians total

Uji Reliabilitas menggunakan koefisien Cronbach's Alpha dengan bantuan SPSS 23.0. Pengujian dilakukan dalam tahapan yaitu dengan membandingkan nilai pada Cronbach's Alpha dengan nilai pada Cronbach's Alpha if item deleted. Untuk menginterpretasikan tingkat keterandalan dari instrumen, digunakan pedoman sebagai berikut:

\section{Uji T}

Untuk menguji hipotesisnya, penulis menggunakan uji t dengan rumus (Sugiyono, 2011) sebagai berikut :

$\mathrm{t}=\frac{r \sqrt{n-2}}{\sqrt{1-r^{2}}}$

Keterangan :

$\mathrm{t}=$ Distribusi $\mathrm{t}$

$r \quad=$ Koefisien korelasi parsial

$r^{2}=$ Koefisien Determinasi

$\mathrm{n} \quad=$ Jumlah data

Kriteria yang digunakan adalah sebagai berikut

Ho diterima jika nilai $t_{\text {hitung }} \leq t_{\text {tabel }}$

Ho ditolak jika nilai thitung $\geq t_{\text {tabel }}$

\section{Koefisien Determinasi}

Besarnya koefisien determinasi dapat dihitung dengan menggunakan rumus sebagai berikut :

$\mathrm{Kd}=r^{2} \times 100 \%$

Dimana :

$\mathrm{Kd}=$ Koefisien determinasi

$\mathrm{r}^{2} \quad=$ Koefisien korelasi

\section{Analisis Regresi Linier Sederhana}

Rumus analisis regresi linier sederhana (Rangkuti, 2011) yaitu :

$\mathrm{Y}=\mathrm{a}+\mathrm{bx}$

IV. ANALISIS DAN PEMBAHASAN

4.1 Uji Validitas

Tabel 1.

Hasil Uji Validitas Pengaruh Iklan Katalog

\begin{tabular}{clccc}
\hline No & \multicolumn{1}{c}{ Pertanyaan } & $\mathrm{R}_{\text {hitung }}$ & $\mathrm{r}_{\text {tabel }}$ & Keterangan \\
\hline 1 & $\begin{array}{l}\text { Menurut saya iklan katalog Indomaret mampu memberikan } \\
\text { informasi tentang produk yang ditawarkan }\end{array}$ & 0,473 & 0,196 & valid \\
\hline 2 & $\begin{array}{l}\text { Menurut saya iklan katalog Indomaret mempermudah saya } \\
\text { untuk mencari produk yang saya butuhkan }\end{array}$ & 0,378 & 0,196 & valid \\
\hline 3 & $\begin{array}{l}\text { Menurut saya bahasa yang digunakan dalam iklan katalog } \\
\text { Indomaret jelas dan mudah dimengerti }\end{array}$ & 0,259 & 0,196 & valid \\
\hline 4 & $\begin{array}{l}\text { Menurut saya bahasa yang digunakan dalam iklan katalog } \\
\text { Indomaret sesuai dengan aturan yang berlaku }\end{array}$ & 0,433 & 0,196 & valid \\
\hline 5 & $\begin{array}{l}\text { Menurut saya penampilan atau visual iklan katalog } \\
\text { Indomaret sangat menarik }\end{array}$ & 0,601 & 0,196 & valid \\
\hline 6 & $\begin{array}{l}\text { Menurut saya iklan Katalog membuat saya memberikan } \\
\text { perhatian terhadap iklan katalog yang ada (atau hanya } \\
\text { sekedar mengambil dan dimasukkan ke keranjang belanja }\end{array}$ & 0,600 & 0,196 & valid \\
\hline
\end{tabular}




\begin{tabular}{lllll}
\hline & atau tas) & & & \\
\hline 7 & Iklan katalog membuat saya berbelanja di Indomaret & 0,486 & 0,196 & valid \\
\hline 8 & $\begin{array}{l}\text { Saya lebih memilih membeli produk di Indomaret } \\
\text { dibanding tempat lain }\end{array}$ & 0,563 & 0,196 & valid \\
\hline 9 & $\begin{array}{l}\text { Menurut saya iklan katalog Indomaret membuat saya ingin } \\
\text { melihat-lihat produk yang ditawarkan }\end{array}$ & 0,439 & 0,196 & valid \\
\hline 10 & $\begin{array}{l}\text { Menurut saya iklan katalog Indomaret membuat saya ingin } \\
\text { melihat-lihat walaupun sedang tidak membutuhkan } \\
\text { sesuatu }\end{array}$ & 0,606 & 0,196 & valid \\
\hline
\end{tabular}

Sumber : Data diolah, 2019

Tabel 2.

Hasil Uji Keputusan Pembelian

\begin{tabular}{llccc}
\hline No & \multicolumn{1}{c}{ Pertanyaan } & Rhitung & rtabel & Keterangan \\
\hline 1 & $\begin{array}{l}\text { Saya sedang membutuhkan suatu barang dan langsung } \\
\text { teringat Indomaret }\end{array}$ & 0,640 & 0,196 & valid \\
\hline 2 & $\begin{array}{l}\text { Saya berencana membeli produk yang saya butuhkan di } \\
\text { Indomaret }\end{array}$ & 0,716 & 0,196 & valid \\
\hline 3 & $\begin{array}{l}\text { Saya mencari informasi tentang barang yang saya } \\
\text { butuhkan }\end{array}$ & 0,613 & 0,196 & valid \\
\hline 4 & $\begin{array}{l}\text { Saya mencari informasi tentang barang yang saya } \\
\text { butuhkan dari katalog Indomaret }\end{array}$ & 0,635 & 0,196 & valid \\
\hline 5 & $\begin{array}{l}\text { Saya memutuskan akan membeli produk yang saya } \\
\text { butuhkan }\end{array}$ & 0,509 & 0,196 & valid \\
\hline 6 & $\begin{array}{l}\text { Saya memutuskan akan membeli produk yang saya } \\
\text { butuhkan di Indomaret }\end{array}$ & 0,544 & 0,196 & valid \\
\hline 7 & $\begin{array}{l}\text { Menurut saya berbelanja di Indomaret memberikan saya } \\
\text { kepuasan }\end{array}$ & 0,623 & 0,196 & valid \\
\hline 8 & Saya akan kembali berbelanja lagi di Indomaret & 0,545 & 0,196 & valid \\
\hline
\end{tabular}

Sumber : Data diolah 2019

\subsection{Uji Reliabilitas}

Tabel 3.

Nilai Cronbach Alpha

\begin{tabular}{llll}
\hline \multicolumn{1}{c}{ Variabel } & Cronbach Alpha & Kriteria & Status \\
\hline Iklan Katalog & 0,809 & $<0,60$ & Reliabilitas baik \\
\hline Keputusan Pembelian & 0,856 & $<0,60$ & Reliabilitas baik \\
\hline Sumber: Data diolah, 2019 & & &
\end{tabular}

Tabel 3 menunjukkan bahwa nilai koefisien Alpha Cronbach pada masing-masing variabel iklan katalog dan keputusan pembelian memiliki nilai $<0,60$. Nilai koefisien Alpha Cronbach untuk variabel iklan katalog adalah sebesar 0,809 dan keputusan pembelian sebesar 0,840 memiliki nilai reliabilitas yang baik sehingga dapat digunakan dalam pengujian penelitian.

\subsection{Uji t}


Tabel 4.

Hasil Uji Coefficientsa

\begin{tabular}{|c|c|c|c|c|c|}
\hline \multirow[t]{2}{*}{ Model } & \multicolumn{2}{|c|}{$\begin{array}{l}\text { Unstandardized } \\
\text { Coefficients }\end{array}$} & \multirow{2}{*}{$\begin{array}{c}\text { Standardized } \\
\text { Coefficients } \\
\text { Beta }\end{array}$} & \multirow[t]{2}{*}{$t$} & \multirow[t]{2}{*}{ Sig. } \\
\hline & B & Std. Error & & & \\
\hline (Constant) & 2,242 & 2,137 & & 1,049 & 297 \\
\hline Iklan Katalog & ,766 &, 067 &, 757 & 11,466 &, 000 \\
\hline
\end{tabular}

a. Dependent Variable: Keputusan Pembelian

Sumber : SPSS 23.0 diolah, 2019

Dari uji $t$ tersebut diperoleh nilai thitung $11,466>t_{\text {tabel }} 1,660$ dan nilai signifikasi $0.000<$ 0.05 maka Ho ditolak karena thitung lebih besar dari t tabel serta iklan katalog dinyatakan berpengaruh dan signifikan terhadap keputusan pembelian. Analisis regresi linear sederhana adalah analisis untuk mengukur besarnya $Y=$ $2,242+0,766 X$

\subsection{Analisis Koefisien Determinasi}

Tabel 5.

Hasil Uji Model Summaryb

\begin{tabular}{lrrrr}
\hline Model & $\mathrm{R}$ & $\mathrm{R}$ Square & Adjusted R Square & Std. Error of the Estimate \\
\hline 1 &, $757^{\mathrm{a}}$ &, 573 &, 569 & 2,60954
\end{tabular}

a. Predictors: (Constant), Iklan Katalog

b. Dependent Variable: Keputusan Pembelian

Sumber : SPSS 23.0 diolah, 2019

Adjusted R2 adalah 0,573 hal ini berarti $57,3 \%$ variabel iklan katalog dapat dijelaskan oleh variabel Independen. Sedangkan sisanya $(100 \%-57,3 \%=42,7 \%)$ dijelaskan oleh sebab sebab yang lain diluar model.

\subsection{Hasil Penelitian}

Berdasarkan analisis pada data indikator konsep didapatkan hasil sebagai berikut:

Tabel 6.

Nilai Rata-rata Konsep Indikator

\begin{tabular}{|c|c|c|c|c|c|}
\hline \multirow{2}{*}{$\begin{array}{l}\text { Konsep } \\
\text { Indikator }\end{array}$} & \multirow{2}{*}{$\begin{array}{c}\text { Butir } \\
\text { Pertanyaan }\end{array}$} & $X$ & \multirow{2}{*}{$\begin{array}{l}\text { Konsep } \\
\text { Indikator }\end{array}$} & \multirow{2}{*}{$\begin{array}{c}\text { Butir } \\
\text { Pertanyaan }\end{array}$} & $Y$ \\
\hline & & Iklan Katalog & & & Keputusan Pembelian \\
\hline \multirow{2}{*}{1} & 1 & 3,15 & \multirow{2}{*}{1} & 1 & 3,20 \\
\hline & 2 & 3,14 & & 2 & 3,15 \\
\hline \multirow{2}{*}{2} & 1 & 3,17 & \multirow{3}{*}{2} & 1 & 3,39 \\
\hline & 2 & 3,12 & & 2 & 310 \\
\hline \multirow{2}{*}{3} & 1 & 3,25 & & 2 & 3,10 \\
\hline & 2 & 3,27 & \multirow{3}{*}{3} & 1 & 356 \\
\hline \multirow{2}{*}{4} & 1 & 3,24 & & 1 & 0,50 \\
\hline & 2 & 3,16 & & 2 & 3,15 \\
\hline \multirow{2}{*}{5} & 1 & 3,03 & \multirow{2}{*}{4} & 1 & 3,49 \\
\hline & 2 & 3,21 & & 2 & 3,52 \\
\hline
\end{tabular}

Sumber : Diolah, 2019

Ket:

Biru : tertinggi

Kuning : terendah

Gambar 3. 


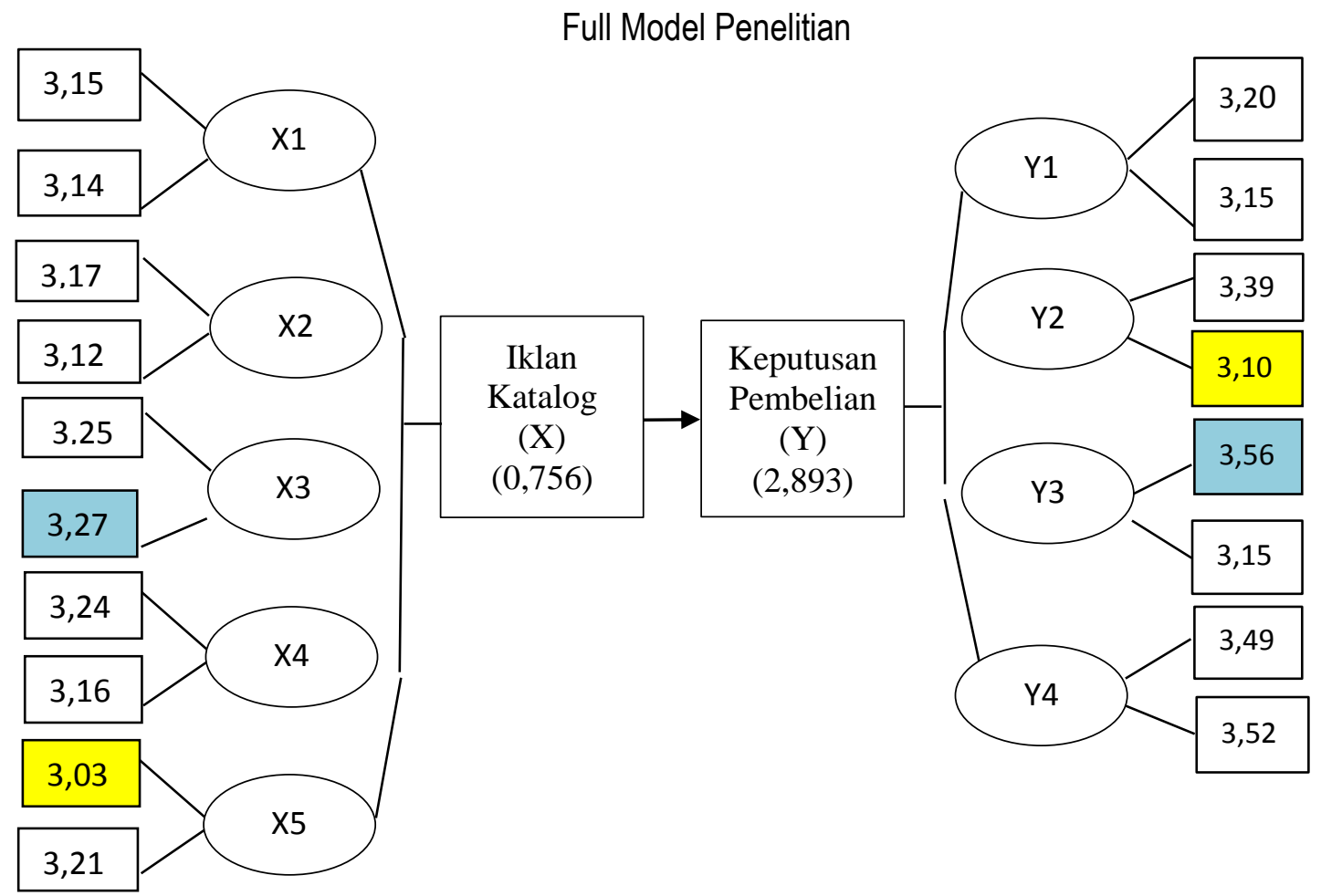

Sumber : Diolah penulis, 2019

Berdasarkan gambar diatas, faktor iklan katalog $(X)$ yang mempengaruhi keputusan pembelian $(Y)$ dengan elemen $X$ yang paling dominan bernilai 3,27 pada indikator ke-3 tentang keyakinan konsumen dalam memilih berbelanja di Indomaret yang memodifikasi $Y$ pada elemen tentang keputusan pembelian produk yang dibutuhkan di Indomaret ada pada indikator evaluasi alternatif yang bernilai 3,56 .

\section{SIMPULAN DAN SARAN}

\subsection{Simpulan}

Berdasarkan nilai $R$ square $\left(R^{2}\right)$ sebesar 0,573 hal ini berarti $57,3 \%$ variabel iklan katalog dapat dijelaskan oleh variabel Independen. Menurut nilai rata-rata data tabulasi kuesioner, nilai terendah dari masingmasing variabel ada pada indikator iklan katalog tentang daya tarik yaitu dan indikator keputusan pembelian tentang pencarian informasi produk. Sedangkan untuk nilai tertinggi pada variabel iklan katalog adalah indikator keyakinan dan pada variabel keputusan pembelian dengan indikator evaluasi alternatif Dari hasil data penelitian di atas, maka penulis menyimpulkan bahwa iklan katalog dapat digunakan untuk menarik konsumen agar melakukan pembelian di Indomaret Sindangsari Tanjung Bintang.

\subsection{Saran}

1. Saran Perbaikan, hendaknya Indomaret Sindangsari Tanjung Bintang perlu mengadakan bazar yang dilakukan secara rutin di depan toko untuk menarik konsumen agar lebih sering berbelanja. Kemudian, kegiatan promosi dengan cara mengadakan pawai oleh Si Domar dapat dilakukan untuk membuat orang-orang membicarakannya dan tertarik untuk datang ke Indomaret.

2. Saran Peningkatan, ,eningkatkan pelayanan sehingga membuat konsumen nyaman dalam memilih produk sehingga melakukan pembelian setra penambahan jenis produk agar semakin menambah jumlah konsumen.

\section{DAFTAR PUSTAKA}

Arikunto, Suharsimi. 2010. Prosedur Penelitian: Suatu Pendekatan Praktek. Jakarta:Rineka Cipta. 
Bharata, Addy Sukma \& Dendy Triadi. 2010. Ayo Bikin Iklan: Memahami Teori dan Praktek Iklan Media Lini Bawah. Jakarta: PT. Elex Media Komputindo.

Ghozali, Imam. 2013. Aplikasi Analisis Multivariate dengan Program IBM SPSS

21 Update PLS Regresi. Semarang: Badan Penerbit UniversitasDiponegoro.

Junaedi, Fajar. 2013. Jurnalisme Penyiaran dan Reportase Televisi. Jakarta: Kencana Prenada Media Group.

Kotler, Philip. 2012. Manajemen Pemasaran. Edisi tiga belas Bahasalndonesia.Jilid 1 dan 2. Jakarta: Erlangga.

Rangkuti, Freddy. 2011. SWOT Balance scorecard. Jakarta: PT Gramedia Pustaka Utama.

Sumarwan, Ujang. 2011. Perilaku Konsumen. Edisi Kedua. Bogor: Ghalia Indonesia.

Sangadji, E.M., dan Sopiah. 2013. Prilaku Konsumen: Pendekatan Praktis

Disertai:Himpunan Jurnal Penelitian. Yogyakarta: Penerbit Andi.

Sugiyono. 2011. Metode Penelitian Kuantitatif, Kualitatif dan R\&D. Bandung: Afabeta

Suharyadi, \& Purwanto S.K. 2015. Statistik Untuk Ekonomi Dan Keuangan Modern. Jakarta. Salemba Empat.

Sumarwan, Ujang dkk. 2011. Riset Pemasaran dan Konsumen : Panduan Riset dan Kajian : Kepuasan, Perilaku Pembelian, Gaya Hidup, Loyalitas dan Persepsi Resiko. Bogor: PT Penerbit IPB Press.

Swastha, Basu \& Handoko, Hani. 2011. Manajemen Pemasaran-Analisis
Perilaku Konsumen. Yogyakarta. BPFE.

Tinarbuko, Sumbo. 2015. DEKAVE Desain Komunikasi Visual - Penanda Zaman Masyarakat Global. Yogyakarta : CAPS (Center for Academic Publishing Service)

Tjiptono, Fandy. 2011. Strategi Pemasaran. Edisi 3. Yogyakarta : ANDI.

Warren J. Keegan, Mark C. Green. 2017. Global Marketing. 9th Edition. Harlow: Pearson Education Limited.

Website :

https://www.cnnindonesia.com/ekonomi/201901 15142736-95-360953/deretan-ritelyang-tutup-lapak-sepanjang-2017-2019 https://economy.okezone.com/read/2019/01/18/ 320/2006182/banyak-ritel-gulung-tikarmenko-darmin-ada-e-commerce

https://www.maxmanroe.com/vid/marketing/pen gertian-strategi-pemasaran.html

https://m.majalahfranchise.com/article/15/impia n-dominasi-brand-lokal-teladan-darialfamart

http://indomaret.co.id/korporat/seputarindomaret/peduli-danberbagi/2014/01/16/sejarah-dan-visi/

http://indoritel.co.id/profile/overview/ https://sagalaartweb.blogspot.com/2011/07/apa -itu-katalog.html

https://junaidichaniago.wordpress.com/2010/04/ 21/download-tabel-t-untuk-d-f-1-200/ https://junaidichaniago.files.wordpress.com/201 0/05/tabel-r.pdf 